\section{Peroxide solvation by a toroidal lithium inverse crown ether complex assembled by multidentate polyimido sulfonates $\dagger$}

\author{
Margret M. Meinholz, Elena Carl, Ella Kriemen and Dietmar Stalke*
}

Received 22nd July 2011, Accepted 18th August 2011

DOI: $10.1039 / \mathrm{clcc14466a}$

In this communication we present the synthesis of the inverse crown ether complex $\left[\mathrm{Li}_{2} \mathrm{O}_{2} \cdot \mathrm{Li}_{4}\left\{\mathrm{CH}_{2}\left(\mathrm{~N}(\mathrm{Me}) \mathrm{CH}_{2} \mathrm{~S}(\mathrm{~N} t \mathrm{Bu})_{2}\right)_{2}\right\}_{2}\right]$ (1) which is able to accommodate peroxide in a torus of lithium ions.

Soon after the synthesis of crown ethers, ${ }^{1}$ preferentially designed to coordinate alkali metals the first report on anionic solvation was published (a in Scheme 1). ${ }^{2}$ These two key building blocks paved the way to a new area of coordination chemistry, supramolecular chemistry based on molecular recognition. ${ }^{3}$ Since then anion recognition is an emerging research topic, ${ }^{4}$ focusing mainly on two different branches: anion- $\pi$-acidic $\mathrm{N}$-heteroaromatic ring interactions ${ }^{5}$ and anion-Lewis acidic metallacycles incorporation. [12]mercuracarborand-4 was unearthed to accommodate one or two halide anions and coined an anti-crown (b in Scheme 1). ${ }^{6}$ Cyclic mixed metal amides like $\left[\mathrm{Li}_{2} \mathrm{Mg}_{2}\left\{\mathrm{~N}\left(\mathrm{SiMe}_{3}\right)_{2}\right\}_{4}\right]^{2+}$ were synthesised and encompass oxide $\mathrm{O}^{2-}$ or peroxide $\mathrm{O}_{2}^{2-}$ (c in Scheme 1$)^{7}$ These oxygen scavengers
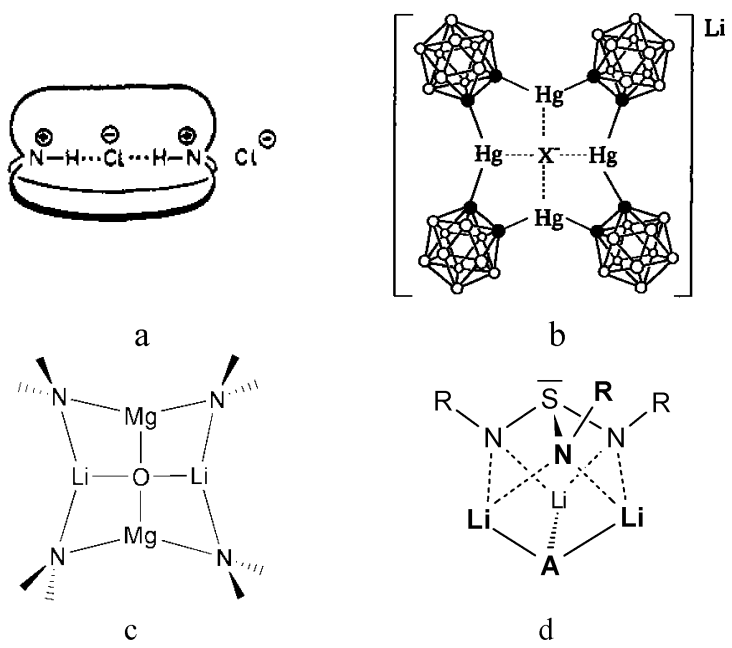

Scheme 1 Lead motifs in anion recognition in supramolecular chemistry.

Institut für Anorganische Chemie der Universität Göttingen,

Tammannstraße 4, 37077, Göttingen, Germany.

E-mail: dstalke@chemie.uni-goettingen.de; Fax: +49-551-39-3459;

Tel: + 49-551-39-3000

$\dagger$ Electronic supplementary information (ESI) available: CCDC 831541.

For crystallographic data in CIF or other electronic format see DOI: $10.1039 / \mathrm{clccl} 4466 \mathrm{a}$ were called inverse crown ether complexes (ICEs) and the ether cleavage reaction was identified to be the oxygen source. ${ }^{8}$

Later they were synthesised by a redox method from air $/ \mathrm{O}_{2}$ as well to give a mixed metal $\left[\mathrm{Li}_{2} \mathrm{Mn}_{2}(\mathrm{TMP})_{4}\right]$, TMP $=2,2,4,4-$ tetra-methylpiperidide, complex. ${ }^{9}$ Recently this class of compounds was tailored to halide deficient amido metal anionic crowns, accepting a single halide in the centre of a $[\text { Li(amide) }]_{5}$-five membered ring. ${ }^{10}$ In addition to these toroidal ICEs there are inverse tripods $\left[\mathrm{Li}_{3}(\mathrm{RN})_{3} \mathrm{~S}\right]^{+}$based on lithium triazasulfite $^{11}$ capable to coordinate just one hemi-sphere of an anion like methanide, ${ }^{12}$ halide ${ }^{13}$ azide $^{14}$ or enolate ${ }^{15}$ (d in Scheme 1).

In this communication we report on a new Lewis acidic inverse crown ether complex, generated in a double addition approach of a $\alpha$-dilithiated tertiary diamine across the multiple bonds of two distinct $\mathrm{S}=\mathrm{N}$ units of sulfurdiimide according to Scheme 2. This work is based on our on-going ligand design of main group metal complexes of tridentate polyimido sulfur ligands with phosphorus ${ }^{16}$ and nitrogen ${ }^{17}$ side-arms. These mono-anionic ligands have the general formula $\left\{\mathrm{R}_{2}^{1} \mathrm{PCH}_{2} \mathrm{~S}\left(\mathrm{NR}^{2}\right)_{2}\right\}^{-}$ $\left(\mathrm{R}^{1}=\mathrm{Me}, \mathrm{Ph} ; \mathrm{R}^{2}=t \mathrm{Bu}, \mathrm{SiMe}_{3}\right)$ and $\left\{\mathrm{R}_{2}^{1} \mathrm{~N}(\text { spacer }) \mathrm{S}\left(\mathrm{NR}^{2}\right)_{2}\right\}^{-}$ $\left(\mathrm{R}^{1}=\mathrm{Me} ; \mathrm{R}^{2}=t \mathrm{Bu}, \mathrm{SiMe}_{3}\right.$, spacer $\left.=0,\left(\mathrm{CH}_{2}\right)_{n}, \mathrm{C}_{6} \mathrm{H}_{4}\right)$. Metal complexes are accessible via salt elimination from e.g. the monomer $\left[(\right.$ tmeda $)\left\{\mathrm{Li}\left(\mathrm{Ph}_{2} \mathrm{PCH}_{2} \mathrm{~S}\left(\mathrm{NSiMe}_{3}\right)_{2}\right\}\right]$ and metal amides. They can $(N, N, P)$ - or $(N, N, N)$-coordinate in a facial fashion to various metals. In the course to widen the route to ligands with even more donor sites TMMDA (tetramethylmethylenediamine) was deprotonated with $t \mathrm{BuLi}$ according to a published procedure. ${ }^{18}$ The double $\alpha$-lithiation of this tertiary amine is feasible because of the pre-coordination of $t \mathrm{BuLi}$ by the substrate. ${ }^{19}$ The lithiated product was suspended in pentane and two equivalents of $\mathrm{S}(\mathrm{N} t \mathrm{Bu})_{2}$ were added slowly at $-78^{\circ} \mathrm{C}$ (Scheme 2) $\ddagger$

After stirring overnight, the suspension was filtered and the resulting light yellow solution stored at $-25^{\circ} \mathrm{C}$ for crystallization. The molecular structure of $\mathbf{1}$ is shown in Fig. 1.§ Interestingly, there was peroxide incorporated in a torus of six lithium cations. No ether cleavage reaction was observed because no ether was present at any stage of the synthesis. The dilithiated aminal is not reacting with oxygen either to give the corresponding alkoxide as a result of the low solubility in pentane. Instead the TMMDA starting material was identified to be the source of oxygen because the compound was handled at any time under inert gas conditions. The amine was only shortly degassed prior to use. 


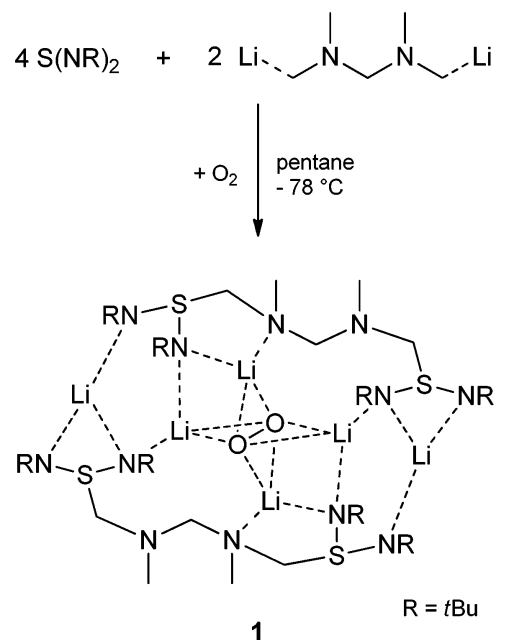

Scheme 2 Preparation of $\left[\mathrm{Li}_{2} \mathrm{O}_{2} \cdot \mathrm{Li}_{4}\left\{\left(\mathrm{CH}_{2}\left(\mathrm{~N}(\mathrm{Me}) \mathrm{CH}_{2} \mathrm{~S}(\mathrm{~N} t \mathrm{Bu})_{2}\right)_{2}\right\}_{2}\right]\right.$ (1).

With the same batch of amine $\mathbf{1}$ was successfully reproduced. The presence of water would most probably have led to the incorporation of $\mathrm{OH}^{-}$rather than $\mathrm{O}_{2}{ }^{2-}$. Properly degassed amines give oxygen-free lithium complexes, accessible to transmetallation reactions. ${ }^{17}$ Here the anticipated dianionic ligand $\left\{\mathrm{CH}_{2}\left(\mathrm{~N}(\mathrm{Me}) \mathrm{CH}_{2} \mathrm{~S}(\mathrm{~N} t \mathrm{Bu})_{2}\right)_{2}\right\}^{2-}$ has formed, with six nitrogen atoms as potential donor sites, accommodating in the centre of two aggregated $\left[\mathrm{Li}_{2}\left\{\left(\mathrm{CH}_{2}\left(\mathrm{~N}(\mathrm{Me}) \mathrm{CH}_{2} \mathrm{~S}(\mathrm{~N} t \mathrm{Bu})_{2}\right)_{2}\right\}\right]_{2}\right.$ units an additional $\mathrm{Li}_{2} \mathrm{O}_{2}$ lithium peroxide moiety. Both oxygen atoms are $\mu$-bridged by the four $\mathrm{Li} 2, \mathrm{Li} 2{ }^{\prime}, \mathrm{Li} 3$ and $\mathrm{Li}^{\prime}{ }^{\prime}$ cations at an average distance of 1.915(4) $\AA$, which is in good agreement with the distance of $190 \mathrm{pm}$ determined in $\mathrm{Li}_{2} \mathrm{O}_{2}$ from IR spectroscopy. Interestingly, there was no formation of the thermodynamically more stable lithium oxide $\left(\Delta H_{\mathrm{f}}=-43.7\right.$ vs. $\left.27.5 \mathrm{kcal} \mathrm{mol}^{-1}\right){ }^{20}$ which could have been anticipated in the presence of oxygen. In the absence of the toroidal ligand and the pre-organisation of the $\mathrm{Li}_{4}$ square in the centre of the structure the formation and precipitation of $\mathrm{Li}_{2} \mathrm{O}\left(U=2814 \mathrm{~kJ} \mathrm{~mol}^{-1}\right)$ are anticipated rather than the formation of $\mathrm{Li}_{2} \mathrm{O}_{2}\left(U=2557 \mathrm{~kJ} \mathrm{~mol}^{-1}\right)$, due to the considerably higher lattice energy ${ }^{21}$ and the non-polar solvent pentane. The $\mathrm{O}-\mathrm{O}$ distance of $1.557(5) \AA$ in $\mathbf{1}$ is about $0.1 \AA$ longer than in $\mathrm{H}_{2} \mathrm{O}_{2}(1.453(7) \AA)^{22}$ but only $0.07 \AA$ than in $\mathrm{BaO}_{2}(1.49(4) \AA) .{ }^{23}$ Apparently the ligand shields the reactive peroxide very well and the lipophilic layer provides solubility in non-polar hydrocarbons (Fig. 1, bottom).

Solid-state Raman spectroscopic investigations of $\mathbf{1}$ were performed to obtain an independent additional proof for the existence of $\mathrm{O}_{2}{ }^{2-}$. The Raman spectrum was recorded at an excitation wavelength of $633 \mathrm{~nm}$ and a laser power of $1 \mathrm{~mW}$. Based on our previous Raman spectroscopic experiments and DFT signal assignment in polyimido anions ${ }^{24}$ the vibrations of 1 could be identified and assignment details are given in the experimental. The SN vibrations are located in the area ranging from 700 to $910 \mathrm{~cm}^{-1}$. The vibration of the peroxide is assigned to a strong signal at $745 \mathrm{~cm}^{-1}$, closely accompanied by a weak signal at $711 \mathrm{~cm}^{-1}$, assigned to the $\mathrm{Li}-\mathrm{O}$ stretching mode. While the $\mathrm{O}-\mathrm{O}$ stretching vibrations of $\mathrm{O}_{2}$ and $\mathrm{O}_{2}{ }^{-}$are located predominantly in the area above $1000 \mathrm{~cm}^{-1}$ the related mode in peroxide is of lower energy because the two additional
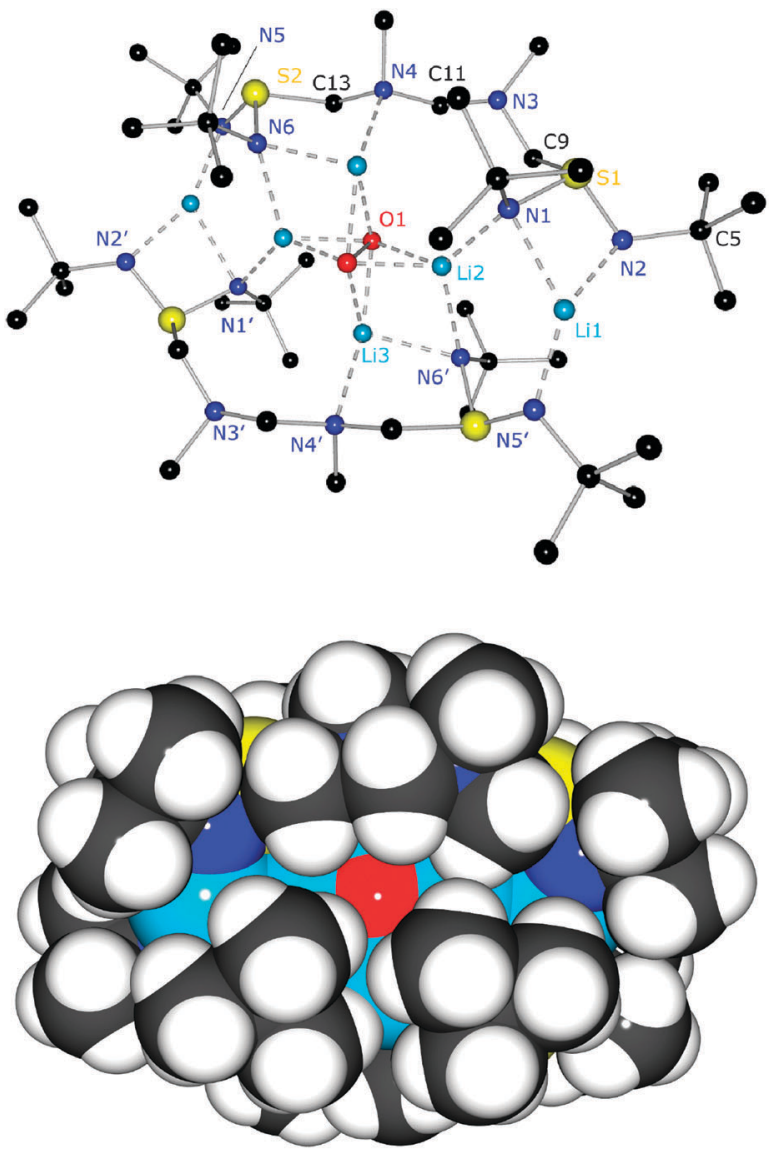

Fig. 1 Structure of $\left[\mathrm{Li}_{2} \mathrm{O}_{2} \cdot \mathrm{Li}_{4}\left\{\left(\mathrm{CH}_{2}\left(\mathrm{~N}(\mathrm{Me}) \mathrm{CH}_{2} \mathrm{~S}(\mathrm{~N} t \mathrm{Bu})_{2}\right)_{2}\right\}_{2}\right]\right.$ (1), ball-and-stick model (top) and space filling model (bottom); selected bond lengths $(\AA)$ and angles $\left({ }^{\circ}\right)$ : S1-N1 1.643(2), S1-N2 1.620(2), S1-C9 1.840(2), O1-O1' 1.560(3), Li2-O1 1.906(4), Li3-O1 1.928(4), Li1-N1 2.175(5), Li1-N2 1.963(5); N1-S1-N2 102.23(10), Li2-O1-Li2' 131.90(13), Li2-O1-Li3' 86.8(2), O1-Li2-O1' 48.10(12).

electrons decrease the bond order and populate antibonding molecular orbitals. ${ }^{20,25}$

In quintessence we provide a $\mathrm{Li}_{4}$ torus, organized and maintained by a polydentate $\mathrm{S}$-centered $\mathrm{N}$-donating ligand, capable to accommodate thermodynamically unfavoured lithium peroxide.

We acknowledge funding from the DFG Priority Programme 1178, the DNRF funded Centre of Materials Crystallography and the doctoral programme Catalysis for Sustainable Synthesis, provided by the Land Niedersachsen (E. C). We thank Prof. M. Schmitt and Dr. N. Tarcea, Universität Jena, for recording the Raman spectrum.

\section{Notes and references}

$\ddagger$ Experimental data of 1: $\left[\left\{\mathrm{LiH}_{2} \mathrm{CN}(\mathrm{Me})\right\}_{2} \mathrm{CH}_{2}\right](0.20 \mathrm{~g}, 1.75 \mathrm{mmol}$, 2.0 eq.) was suspended in pentane $(8 \mathrm{~mL})$ and $\mathrm{S}(\mathrm{N} t \mathrm{Bu})_{2}(0.61 \mathrm{~g}$, $3.50 \mathrm{mmol}, 4.0$ eq.) was slowly added at $-78{ }^{\circ} \mathrm{C}$. The solution was allowed to warm to rt overnight, filtered and reduced in volume. Upon storage at $-25^{\circ} \mathrm{C}$ colourless crystals were obtained after several hours. Yield: $0.62 \mathrm{~g}, 0.64 \mathrm{mmol}, 73 \%$; Elemental analysis (found: $\mathrm{C}, 51.86 ; \mathrm{H}$, $10.25 ; \mathrm{N}, 17.34 ; \mathrm{S}, 13.74(\%)$; calc. C, $51.94 ; \mathrm{H}, 9.96 ; \mathrm{N}, 17.31 ; \mathrm{S}, 13.21$ $(\%)) ; \delta_{\mathrm{H}}\left(300.13 \mathrm{MHz} ; \mathrm{C}_{6} \mathrm{D}_{6}\right): 1.40\left(\mathrm{~s}, 72 \mathrm{H}, \mathrm{NC}\left(\mathrm{CH}_{3}\right)_{3}\right), 2.10(\mathrm{~s}, 12 \mathrm{H}$, $\left.\mathrm{NCH}_{3}\right), 2.97\left(\mathrm{~s}, 4 \mathrm{H}, \mathrm{NCH}_{2} \mathrm{~N}\right), 3.13\left(\mathrm{~s}, 8 \mathrm{H}, \mathrm{NCH}_{2} \mathrm{~S}\right) ; \delta_{\mathrm{C}}(125.76 \mathrm{MHz}$; $\left.\mathrm{C}_{6} \mathrm{D}_{6}\right): 33.95\left(\mathrm{NC}\left(\mathrm{CH}_{3}\right)_{3}\right), 47.10\left(\mathrm{~N}\left(\mathrm{CH}_{3}\right)_{2}\right), 53.44\left(\mathrm{C}\left(\mathrm{CH}_{3}\right)_{3}\right), 86.39$ $\left(\mathrm{SCH}_{2} \mathrm{~N}\right), 88.15\left(\mathrm{NCH}_{2} \mathrm{~N}\right) ; \delta_{\mathrm{Li}}\left(116.46 \mathrm{MHz}, \mathrm{C}_{6} \mathrm{D}_{6}\right)$ : one broad signal at 2.53; Raman spectrum of $1\left(\mathrm{~cm}^{-1}\right) 195.6 \mathrm{w},\left(\mathrm{CC}_{3}\right.$ bend); $254.5 \mathrm{~m}$, 
(SNC out of plane bend); $416.7 \mathrm{w},\left(\mathrm{CC}_{3}\right.$ bend); $500.2 \mathrm{w}$, (SNC in plane bend); $711.3 \mathrm{w}$, ( $\mathrm{LiO}$ stretch); $745.8 \mathrm{~s},\left(\mathrm{O}_{2}{ }^{2-}\right.$ (sym)); $844.6 \mathrm{w},\left(\mathrm{CC}_{3}\right.$ stretch); $888.7 \mathrm{~m},\left(\mathrm{SN}_{2}\right.$ stretch (asym)); $907.0 \mathrm{~m},\left(\mathrm{SN}_{2}\right.$ stretch (asym)); $1197.8 \mathrm{w}$, (CN stretch); $1222.7 \mathrm{w},\left(\mathrm{CN}\right.$ stretch); $1444.3 \mathrm{~m},\left(\mathrm{CH}_{3}\right.$ out-of-phase def.); 2884.7 s, $\left(\mathrm{CH}_{3}\right.$ out-of-phase def.); $2949.7 \mathrm{~s},\left(\mathrm{CH}_{3}\right.$ out-of-phase def.). $\S$ Crystallographic details for 1 : shock cooled crystals were selected and applied to the diffractometer under cryogenic conditions using the X-TEMP-2 [T. Kottke, D. Stalke, J. Appl. Crystallogr. 1993, 26, 615; D. Stalke, Chem. Soc. Rev. 1998, 27, 171.]. The structures were solved by direct methods (SHELXS) and refined on $\mathrm{F}^{2}$ using the full-matrix least-squares methods of SHELXL [G. M. Sheldrick, Acta Crystallogr. Sect. A 2008, 64, 112]; $\mathrm{C}_{42} \mathrm{H}_{96} \mathrm{Li}_{6} \mathrm{~N}_{12} \mathrm{O}_{2} \mathrm{~S}_{4}, M=971.19 \mathrm{~g} \mathrm{~mol}^{-1}$, monoclinic, space group $P 2_{1} / c, a=8.6080(9), b=14.0907(14)$, $c=24.267(3) \AA, \beta=99.829(2)^{\circ}, V=2900.2(6) \AA^{3}, Z=2, \rho_{\text {calc }}=$ $1.110 \mathrm{Mg} \mathrm{m}^{-3}, \mu=0.206 \mathrm{~mm}^{-1}, F(000)=1056, \theta$ range $=$ $1.68-25.72^{\circ}, 56834$ reflections measured, 5526 independent, $R_{1}(I>$ $2 \sigma(I))=0.0491, \mathrm{w} R_{2}(I>2 \sigma(I))=0.1056, \mathrm{GoF}=1.073$, diff. peak $/$ hole $0.623 /-0.419 \mathrm{e} \mathrm{A}^{-3}$. CCDC 831541 .

1 C. J. Pedersen, J. Am. Chem. Soc., 1967, 89, 7017.

2 C. H. Park and H. E. Simmons, J. Am. Chem. Soc., 1968, 90, 2431.

3 J.-M. Lehn, Supramolecular Chemistry: Concepts and Perspectives, VCH, Weinheim, 1995.

4 Anion Recognition in Supramolecular Chemistry in Top. Heterocycl. Chem., ed. P. A. Galen and W. Dehaen, 2010, 24.

5 for review see: T. J. Mooibroek, C. A. Black, P. Gamez and J. Reedijk, Cryst. Growth Des., 2008, 8, 1082.

6 for review see: M. F. Hawthorne and Z. Zheng, Acc. Chem. Res., 1997, 30, 267.

7 for review see: R. E. Mulvey, Chem. Commun., 2001, 1049.

8 R. E. Mulvey, V. L. Blair, W. Clegg, A. R. Kennedy, J. Klett and L. Russo, Nat. Chem., 2010, 2, 588.
9 A. R. Kennedy, J. Klett, R. E. Mulvey, S. Newton and D. S. Wright, Chem. Commun., 2008, 308.

10 A. R. Kennedy, R. E. Mulvey, C. T. O'Hara, G. M. Robertson and S. D. Robertson, Angew. Chem., 2011, 123, 8525 (Angew. Chem., Int. Ed., 2011, 50, 8375).

11 R. Fleischer, S. Freitag, F. Pauer and D. Stalke, Angew. Chem., 1996, 108, 208 (Angew. Chem., Int. Ed. Engl., 1996, 35, 204).

12 B. Walfort, L. Lameyer, W. Weiss, R. Herbst-Irmer, R. Bertermann, J. Rocha and D. Stalke, Chem.-Eur. J., 2001, 7, 1417.

13 R. Fleischer, S. Freitag and D. Stalke, J. Chem. Soc., Dalton Trans., 1998, 193.

14 R. Fleischer and D. Stalke, Chem. Commun., 1998, 343.

15 B. Walfort, S. K. Pandey and D. Stalke, Chem. Commun., 2001, 1640.

16 M. M. Meinholz, S. K. Pandey, S. M. Deuerlein and D. Stalke, Dalton Trans., 2011, 40, 1662.

17 M. M. Meinholz, M. Klemmer, E. Kriemen and D. Stalke, Chem.-Eur. J., 2011, 17, 9415.

18 H. H. Karsch, Chem. Ber., 1996, 129, 483.

19 (a) V. Snieckus, Chem. Rev., 1990, 90, 879; M. C. Whisler, S. MacNeil, V. Snieckus and P. Beak, Angew. Chem., 2004, 116, 2256 (Angew. Chem., Int. Ed., 2004, 43, 2206); (b) C. Strohmann and V. H. Gessner, Angew. Chem., 2007, 119, 8429 (Angew. Chem., Int. Ed., 2007, 46, 8281).

20 D. White, K. S. Seshadri, D. F. Denver, D. E. Mann and M. J. Linevsky, J. Chem. Phys., 1963, 39, 2463.

21 CRC Handbook of Chemistry and Physics, Taylor \& Francis, Boca Raton, 87 edn, 2006.

22 W. A. Busing and H. A. Levy, J. Chem. Phys., 1965, 42, 3054.

23 S. C. Abrahams and J. Kalnajs, Acta Crystallogr., 1954, 7, 838.

24 R. Fleischer, B. Walfort, A. Gburek, P. Scholz, W. Kiefer and D. Stalke, Chem.-Eur. J., 1998, 4, 2266.

25 L. Vaska, Acc. Chem. Res., 1976, 9, 175. 